\title{
Effects of Temperature and Concentration of Indium within Bulk Cubic InxGa1-XN: Calculation of Steady State Electron Transport by Method of Monte Carlo Simulation
}

\author{
A. Hamdoune* and N. Bachir, Member, IACSIT
}

\begin{abstract}
Many theoretical and experimental works are made on the wurtzite phase of indium nitride (InN), gallium nitride (GaN), aluminum nitride (AIN), and their alloys. On the other side, few experimental data exist for their cubic phases whereas theoretical studies show they are performing more interesting.The purpose of our paper is to study the electron transport within bulk cubic InxGa1-xN, using the method of Monte Carlo simulation.We start by an introduction, and then we present some electron properties of the binary compounds, GaN, InN, AIN, and those of the ternary, InxGa1-xN. In the third section, we give an outline of the method of Monte Carlo simulation. In the fourth section, we calculate the steady-state electron transport in InxGa1-xN, especially the electron drift velocity versus applied electric field, for different percentages of indium in this alloy, at various temperatures. We consider in our simulation, the following scattering mechanisms: acoustic phonon scattering, nonpolar optical phonon scattering (equivalent and nonequivalent intervalley), polar optical phonon scattering, ionized impurity scattering, piezoelectric scattering, and alloy scattering. To validate our results, we compare with some published results and are in good agreement.
\end{abstract}

Index Terms- $\operatorname{In}_{\mathrm{x}} \mathrm{Ga}_{1-\mathrm{x}} \mathrm{N}$, electron transport, electric field, temperature, Monte Carlo.

\section{INTRODUCTION}

The III-nitride compounds, InN, GaN, AlN and their associated ternaries, InxGa1-xN, AlxGa1-xN, and Inx $\mathrm{All}-\mathrm{xN}$, are of great importance in many applications of semiconductor device structures. They have high breakdown voltage for the high output impedance and high saturation velocity, high linearity, good chemical and thermal stabilities, intense internal electric fields and therefore a very high output power in power amplifiers.

They are used in heterojunction field effect transistors HFET, modulated-doped field effect transistors MODFET, and heterojunction bipolar transistors HBT.

$\mathrm{InN}$ and $\mathrm{GaN}$, have high peak velocity, high saturation velocity and low dielectric constants. They are very good

Paper submitted for expertise December 23, 2009.

A. Hamdoune Unity of Research "Materials and Renewable Energies", Faculty of Science, University of Abou-bekr Belkaid, PO Box 230, 13000, Tlemcen, ALGERIA (phone: 00213-43-28-56-86; fax: 00213-43-28-56-85; e-mail: d hamdoune@yahoo.fr or ahamdoune@gmail.com).

N. Bachir Unity of Research "Materials and Renewable Energies", Faculty of Science, University of Abou-bekr Belkaid, PO Box 230, 13000, Tlemcen, ALGERIA (e-mail: nadia_bachir@yahoo.fr). candidates for novel optoelectronic device applications in the visible and ultraviolet frequency range, and they are very attractive for electronic applications for high power, high temperature and high frequency [1].

In order to analyze and improve the design of III-V nitride semiconductor based devices, an understanding of the electron transport which occurs within these materials is necessary.

In our work, we use the method of Monte Carlo simulation for studying the electron transport within the bulk cubic compound InxGa1-xN.

\section{PROPERTIES OF III-NITRIDE COMPOUNDS}

With GaN, AlN, InN, and their ternary compounds, one can obtain a wide variety of compositions for varying their electron and optical properties.

Their originality lies in their anisotropic structures, their strong ionic characters, and their strong lattice mismatches. The specific properties of these III-N materials are originally charges induced by the effects of spontaneous and piezoelectric polarizations, in the interfaces of quantum wells and super lattices. These charges generate in structures, intense electric fields that significantly influence their properties.

They have high saturation drift velocity, low dielectric constants, direct and large gaps; all these properties depend on the composition of the alloy, allowing these materials make connections operating at high temperatures and with intensities breakdown electric field, larger than in other semiconductors.

The optical devices made from III-nitride compounds, emit throughout the visible and ultraviolet frequency range, in particular they allow obtaining the blue color which was the last to reconstitute white light. Indeed, the InAlGaN alloys have a gap ranging between $1.9 \mathrm{eV}(650 \mathrm{~nm})$ and 6.2 $\mathrm{eV}(200 \mathrm{~nm})$, depending on their compositions.

$\mathrm{GaN}$ and $\mathrm{InN}$ in their cubic phases, respectively, have gaps of about $3.29 \mathrm{eV}$ [3] and $1.9 \mathrm{eV}$ [2], at $300 \mathrm{~K}$. Energy between the first upper valley and the lowest point in the conduction band is about $1.5 \mathrm{eV}$ for $\mathrm{GaN}$, and less than $1 \mathrm{eV}$ for InN.

The variation of the band gap energy of the $\operatorname{In}_{x} \mathrm{Ga}_{1-\mathrm{x}} \mathrm{N}$ alloy, as a function of composition, is not linear but quadratic (1). The parameter $\mathrm{b}$ (bowing) is about $1.13 \pm 0.23 \mathrm{eV}$ for cubic $\mathrm{In}_{\mathrm{x}} \mathrm{Ga}_{1-\mathrm{x}} \mathrm{N}$ [4].

$$
\mathrm{E}_{\mathrm{g}}^{\mathrm{In}_{\mathrm{x}} \mathrm{Ga}_{1-\mathrm{x}} \mathrm{N}}=\mathrm{xE}_{\mathrm{g}}^{\mathrm{InN}}+(1-\mathrm{x}) \mathrm{E}_{\mathrm{g}}^{\mathrm{GaN}}-\mathrm{bx}(1-\mathrm{x})
$$


Its lattice parameters can be deduced from those of GaN and InN (see Table I) by Vegard's law (2). Its effective masses, its mechanical coefficients and those of Varshni, can often be deduced by linear interpolation of $\mathrm{GaN}$ and $\mathrm{InN}$ coefficients [4].

$$
\mathrm{a}_{\mathrm{In}_{\mathrm{X}} \mathrm{Ga}_{1-\mathrm{X}} \mathrm{N}}=\mathrm{x} \times \mathrm{a}_{\mathrm{InN}}+(1-\mathrm{x}) \times \mathrm{a}_{\mathrm{GaN}}
$$

TABLE I: THEORETICAL AND EXPERIMENTAL LATTICE PARAMETERS OF CUBIC NITRIDES.

\begin{tabular}{|c|c|c|c|c|}
\hline Material & \multicolumn{3}{|c|}{$\begin{array}{l}\mathrm{a}_{0}(\AA), \text { calculated by empiric } \\
\text { methods }[5]\end{array}$} & Expérimental $\mathrm{a}_{0}(\AA)$ \\
\hline $\mathrm{GaN}$ & 4.423 & 4.462 & 4.452 & $\begin{array}{l}4.50[6] \\
4.53[7]\end{array}$ \\
\hline AlN & 4.301 & 4.392 & 4.34 & $\begin{array}{c}4.38[8] \\
4.3996[9]\end{array}$ \\
\hline InN & 4.996 & 4.392 & 4.981 & $\begin{array}{l}4.98[10] \\
4.97[11]\end{array}$ \\
\hline
\end{tabular}

\section{Monte CARlo Simulation}

The Monte Carlo method is based on a drawing of lots process of interactions sustained by the free carriers during their movement in the compound, from probability laws. It consists to follow the behavior of each electron in real space and in wave-vectors space.

Consider an electron which owns energy $\varepsilon(t)$, wave-vector $\mathrm{k}(\mathrm{t})$, and which is placed in $\mathrm{r}(\mathrm{t})$. Under action of an applied electric field $\mathrm{E}(\mathrm{r}, \mathrm{t})$; its interaction and exchange of energy with the lattice, and the deviation of its trajectory by impurities; this will modify its energy, its wave-vector and its position. Using the mechanic and the electrodynamics laws; we determine the behavior of each electron, in time and space. To be more realistic:

1. We statistically study possible energy exchanges between electrons, modes of lattice vibration and impurities; this allows us to calculate the probability of these interactions and their action on both electron energy and wave-vector.

2. We assume that these interactions are instantaneous. We can move electrons in free-flight under the only effect of electric field, between two shocks. The free-flight time is determined by the drawing of lots. When interaction takes place, we determine its nature by the drawing of lots. In this case, the electron energy and the electron wave-vector are modified. This results in a change of electrons distribution; we then calculate the electric field that results, at enough small time intervals, to assume it constant between two calculations [4]-[5]-[6].

We consider a simplified model of three isotropic and non parabolic bands. The wave-vector and energy of the electron are related by using (3) [7]:

$$
\frac{\hbar^{2} \mathrm{k}^{2}}{2 \mathrm{~m}^{*}}=\varepsilon(1+\alpha \varepsilon)
$$

Where $m^{*}$ is their effective mass in the $\Gamma$ valley, $\hbar k$ denotes the magnitude of the crystal momentum, $\varepsilon$ represents the electron energy, and $\alpha$ is the nonparabolicity factor of the considered valley, given by (4) [7]:

$$
\alpha=\frac{1}{E_{g}}\left(1-\frac{m^{*}}{m_{e}}\right)^{2}
$$

Where $m_{e}$ and $E g$, denote the free electron mass and the energy gap, respectively. $\mathrm{m}_{\mathrm{e}}=0.20 \mathrm{~m} 0$ for $\mathrm{GaN}$, and $\mathrm{m}_{\mathrm{e}}=0.11 \mathrm{~m}_{0}$ for $\mathrm{InN}$ [7].

The longitudinal $\mathrm{V}_{1}$ and transverse $\mathrm{V}_{\mathrm{t}}$, acoustic velocities [2]-[3]-[15] are calculated by using (5) and (6) (where $\rho$ is the density of material, and $\mathrm{C}_{\mathrm{ij}}$ are elastic constants):

$$
\begin{aligned}
& \mathrm{V}_{1}=\left(\mathrm{C}_{1} / \rho\right)^{1 / 2} \\
& \mathrm{Vt}=(\mathrm{Ct} / \rho) 1 / 2
\end{aligned}
$$

The constants, $\mathrm{C}_{1}$ and $\mathrm{C}_{\mathrm{t}}$, are combinations of elastic constants and calculated by using (7) and (8):

$$
\begin{aligned}
& \mathrm{C}_{1}=\left(3 \mathrm{C}_{11}+2 \mathrm{C}_{12}+4 \mathrm{C}_{44}\right) / 5 \\
& \mathrm{C}_{\mathrm{t}}=\left(\mathrm{C}_{11}-\mathrm{C}_{12}+3 \mathrm{C}_{44}\right) / 5
\end{aligned}
$$

The essence of our Monte Carlo simulation algorithm, used to simulate the electron transport within the semiconductor, $\operatorname{In}_{\mathrm{x}} \mathrm{Ga}_{1-\mathrm{x}} \mathrm{N}$, is given by the diagram of Fig. 1; where $\Delta t$ is the free-flight time of electrons, $N_{e}$ is their number, $\lambda(\varepsilon)$ is their total scattering rate, $t_{\text {simul }}$ is the simulation time, and $\mathrm{N}_{\text {simul }}$ is the maximum number of simulated free carriers.

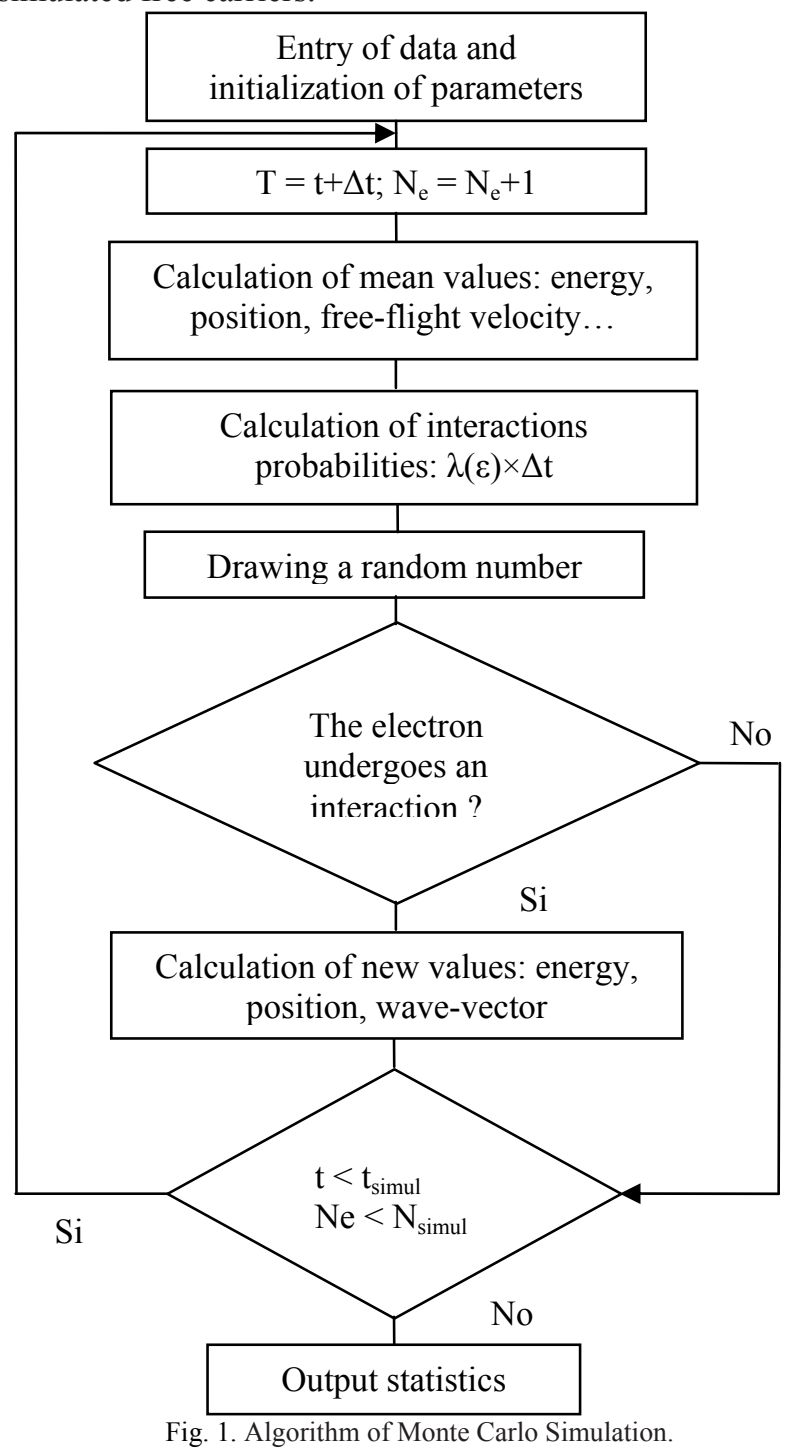

\section{RESUlTS AND DisCUSSION}

We study the electron transport within bulk cubic compound InxGa $1_{-x} \mathrm{~N}$, and the doping concentration being set to $10^{17} \mathrm{~cm}^{-3}$. We use the method of Monte Carlo simulation. Especially, we calculate the electron drift velocity versus applied electric field for indium molar fractions: $\mathrm{x}=0, \mathrm{x}=0.2$, $\mathrm{x}=0.5, \mathrm{x}=0.6, \mathrm{x}=0.8$ and $\mathrm{x}=1$, at various temperatures. 
The scattering mechanisms included within our simulation are: acoustic phonon scattering, no polar optical phonon scattering (equivalent and nonequivalent intervalley), polar optical phonon scattering, ionized impurity scattering, piezoelectric scattering, and alloy scattering. The results are illustrated by Fig. 2 to 7 .

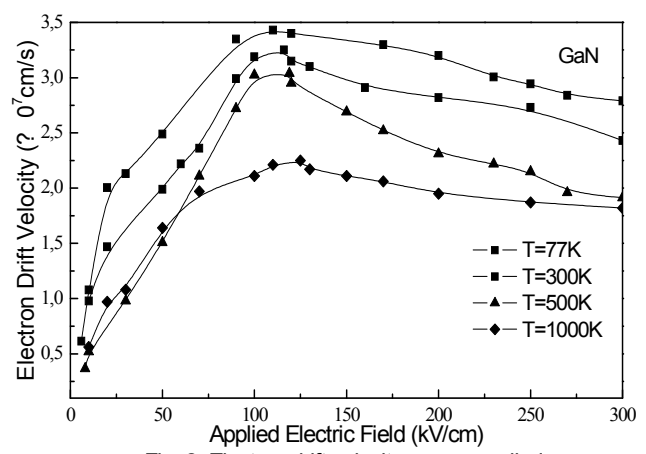

Fig. 2. Electron drift velocity versus applied electric field for $\mathrm{GaN}$, at various temperatures.

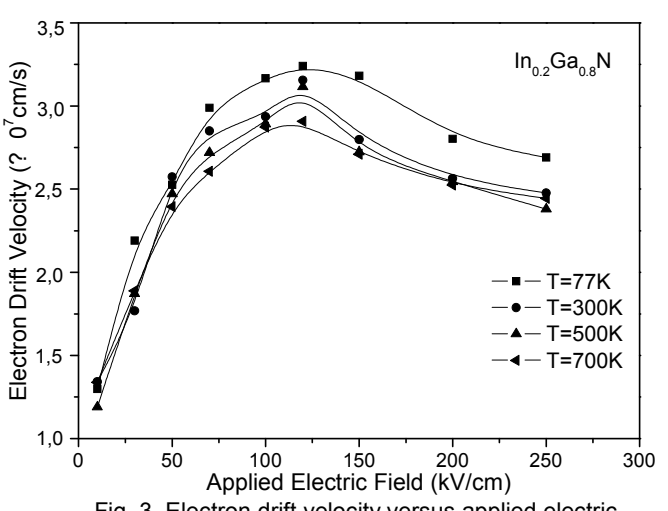

Fig. 3. Electron drift velocity versus applied electric field for $\ln _{0.2} \mathrm{Ga}_{0.8} \mathrm{~N}$, at various temperatures.

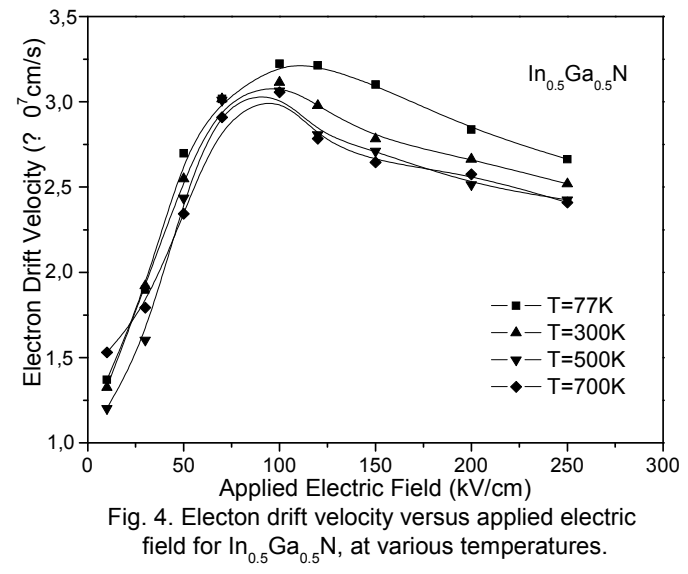

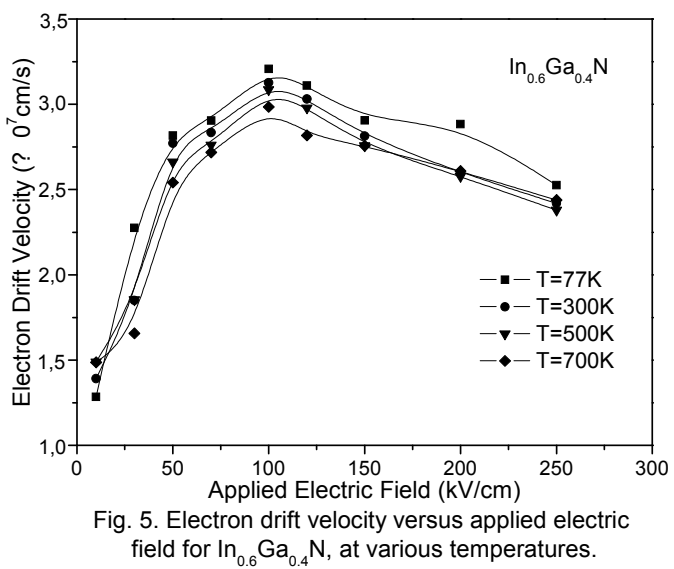
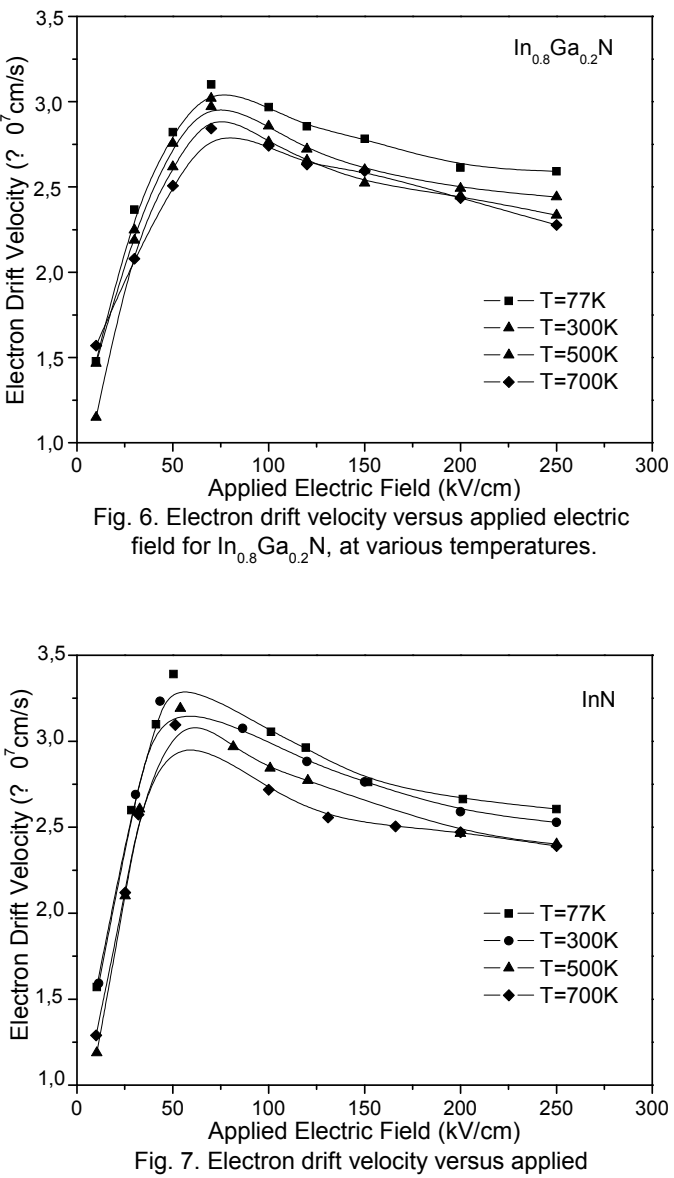
electric field for $\ln \mathrm{N}$, at various temperatures.

- The difference in the temperature dependence of the all compounds is the occupancy of the upper valleys.

- In the case of GaN, the electron drift velocity increases initially with the applied electric field, reaching a maximum of about $3.43 \times 10^{7} \mathrm{~cm} / \mathrm{s}$ at $T=77 \mathrm{~K}, 3.25 \times 10^{7} \mathrm{~cm} / \mathrm{s}$ at $T=$ $300 \mathrm{~K}, 3 \times 10^{7} \mathrm{~cm} / \mathrm{s}$ at $T=500 \mathrm{~K}$ and $2 \times 10^{7} \mathrm{~cm} / \mathrm{s}$ at $T=1000$ $\mathrm{K}$, for an applied electric field strength which is around 110 $\mathrm{kV} / \mathrm{cm}$ and independent of temperature. At this applied electric field strength, the upper valleys begin to become occupied.

-When applied electric field exceeds $110 \mathrm{kV} / \mathrm{cm}$, the electron drift velocity decreases saturating at about $2.9 \times 10^{7}$ $\mathrm{cm} / \mathrm{s}$ at $T=77 \mathrm{~K}, 2.4 \times 10^{7} \mathrm{~cm} / \mathrm{s}$ at $T=300 \mathrm{~K}, 1.9 \times 10^{7} \mathrm{~cm} /$ at $T=500 \mathrm{~K}$, and $1.8 \times 10^{7} \mathrm{~cm} / \mathrm{s}$ at $T=1000 \mathrm{~K}$, for sufficiently high applied electric field strengths; a region of negative differential mobility is observed. 
- Increasing the temperature allows a gain in kinetic energy for electrons; they move more and then collide with other atoms by transferring their energy. The atoms also undergo greater thermal agitation, which increases the possibility of shocks between them and a subsequent decrease in electron velocity.

- With increasing molar fraction of indium, the effective mass of electrons decreases, resulting in an increase of their velocity. Then, they will quickly reach the upper valley where their population becomes important, and their effective mass is larger. Intervalley collisions increase with the population, resulting in a decrease in their drift velocity. The highest velocities are attained for the lowest temperatures; the best one is obtained for a temperature of 77 $\mathrm{K}$ which is the boiling temperature of nitrogen.

- The sensitivity of the velocity-field characteristic associated with bulk cubic $\mathrm{InN}$ is more robust than that associated with GaN to increases in the crystal temperature. This sensitivity is more and more robust with increasing the molar fraction of indium in the $\operatorname{In}_{\mathrm{x}} \mathrm{Ga}_{1-\mathrm{x}} \mathrm{N}$ alloy. For $\mathrm{InN}$, the peak electron drift velocity, which is about $3.3 \times 10^{7} \mathrm{~cm} / \mathrm{s}$ at $T$ $=77 \mathrm{~K}$, only decreases to around $3.24 \times 10^{7} \mathrm{~cm} / \mathrm{s}$ at $T=300 \mathrm{~K}$, $3.18 \times 10^{7} \mathrm{~cm} / \mathrm{s}$ at $T=500 \mathrm{~K}$, and $2.97 \times 10^{7} \mathrm{~cm} / \mathrm{s}$ at $T=700 \mathrm{~K}$. Similarly, the saturation electron drift velocity, which is about $2.6 \times 10^{7} \mathrm{~cm} / \mathrm{s}$ at $T=77 \mathrm{~K}$, only decreases to around 2.52 at $T=300 \mathrm{~K}, 2.4 \times 10^{7} \mathrm{~cm} / \mathrm{s}$ at $T=500 \mathrm{~K}$, and $2.37 \times 10^{7}$ $\mathrm{cm} / \mathrm{s}$ at $T=700 \mathrm{~K}$. At ambient temperature, we obtain the peak electron drift velocity for an applied field electric around $51 \mathrm{kV} / \mathrm{cm}$.

The upper limit, $700 \mathrm{~K}$, is chosen as it is the highest operating temperature which may be expected for $\operatorname{In}_{\mathrm{x}} \mathrm{Ga}_{1-\mathrm{x}} \mathrm{N}$ power devices. As the upper conduction band valleys are so close to the bottom of the conduction band for the case of InN, the thermal energy at $700 \mathrm{~K}\left(k_{B} T \approx 60 \mathrm{meV}\right)$ is enough in order to allow for electrons to transfer into the upper valleys even before an electric field is applied.

-When electrons occupy the upper valleys, intervalley scattering, as well as the upper valleys' larger effective masses, reduce the overall electron drift velocity. This is another reason why the velocity-field characteristic associated with $\mathrm{InN}$ is less sensitive to variations in the crystal temperature than that associated with GaN.

\section{CONCLUSION}

- When the applied electric field is low, the scattering mechanisms are dominated by the absorption of acoustic phonons, ionized impurities and polar optical phonons, which are suppressed to lower temperatures, leading to an improvement in mobility and therefore velocity of electrons. The importance of ionized impurities and acoustic phonons scattering, decreases with temperature, so that the optical polar phonon scattering is the dominant scattering mechanism above $200 \mathrm{~K}$. For temperatures up to $300 \mathrm{~K}$, the hump in the velocity-field characteristics is due to the dispersion of impurities. The population of phonons increases with temperature, the absorption of a polar optical phonon by an electron becomes very likely at low field. Therefore, the dispersion of polar optical phonons dominates at high temperatures, with a reduction in the dispersion of impurities and disappearance of the peak hump.
- When the applied electric field is strong: the electrons have more energy at low temperature. The dispersions of polar optical phonons and acoustic phonons become more likely. For temperatures below $150 \mathrm{~K}$, the dispersion of equivalent polar optical phonons is the dominant mechanism. The dispersion of nonequivalent intervalley phonons begins at $100 \mathrm{~K}$ and becomes the dominant mechanism from $250 \mathrm{~K}$. From $450 \mathrm{~K}$, these four processes dispersions have comparable probabilities.

We compare our results with those of [7]-[15]-[16], they are in good agreement.

-The electron transport within III-V nitride semiconductors, GaN, AlN, InN, and their alloys, is not yet mastered; deeper studies remain to be done. Most troubling is the discrepancy between the results of experiment and those of simulation. There are uncertainties in the material properties and in the underlying physics.

- The most studied of the III-V nitride semiconductors; uncertainty in the band structure remains an issue.

- The energy gap and the effective mass associated with InN continue to fuel debate. Variations in the experimentally determined energy gap, observed from sample to sample, further confound matters.

Given this uncertainty in the band structures associated with the III-V nitride semiconductors, GaN and $\mathrm{InN}$, it is clear that new simulations of the electron transport within these materials will have to be performed once researchers have settled on appropriate band structures.

- Uncertainty in the underlying physics is considerable. The source of the negative differential mobility remains a matter to be resolved. The presence of hot-phonons within these materials, and how such phonons impact upon the electron transport mechanisms within these materials, remains another point of contention.

It is clear that a deeper understanding of these electron transport mechanisms will have to be achieved in order for the next generation of III-V nitride semiconductor based devices to be properly designed.

\section{REFERENCES}

[1] G.Roosen, "Matériaux pour l'Optoélectronique," tome 7, Hermes Science Publications, Paris, 2003.

[2] R. Castagné, J. P. Duchemin, M. Gloanie, Ch. Rhumelhard, "Circuits intégrés en arsenic de gallium, Physique, technologie et conception," Rev. Masson, 1989.

[3] N. Garro, A. Cros, A. Garcia, A. Cantarero, "Optical and vibrational properties of self-assembled GaN quantum dots," Institute of Materials Science, University of Valencia, 2007.

[4] Fabrice Enjalbert, thesis of doctorat, "Etude des hétérostructures semi-conductrices III-nitrures et application au laser UV pompé par cathode à micropointes," University of Grenoble 1, 2004.

[5] Pugh S. K, Dugdale D. J, Brand S and Abram R.A, "Electronic structure calculation on nitride semiconductors," Semicond. SCI, Technol, vol 14, 1999, pp. 23-31.

[6] Y. Zhang et al., "Anomalous strains in the cubic phase GaN films grown on GaAs (001) by metalorganic chemical vapour deposition," J.Appl, Phys, vol. 88, N 6, 2000, pp. 3762-3764.

[7] Stephen K. O’Leary, Brian E. Foutz, Michael S. Shur, Lester F. Eastman, "Steady-State and Transient Electron Transport within the III-V Nitride Semiconductors, GaN, AlN, and InN," A Review J Mater Sci: Mater Electron, vol. 17, 2006, pp. 87-126.

[8] Petrov I, Majob E, Powell R.C and Greene J.E, "Synthesis of metastable epitaxial zinc blend structure AIN by solid reaction," Appl, Phys Letters, vol. 60, $\mathrm{N}^{\circ}$ 20, 1992, pp. 2491-2493.

[9] Okumaru H et al., "Growth of cubic III- nitrides by gas source MBE using atomic nitrogen plasma: GaN AlGaN and AlN," J.Gryst. Growth, vol. $198 / 190,1998$, pp. 390-394. 
[10] Martinez Guerrero, Esteban, "Elaboration en épitaxie par jets moléculaires des nitrures d'éléments III en phase cubique," National Institute of Applied Science, Lyon, 2002.

[11] François Dessenne, "Etude thermique et optimisation des transistors à effet de champ de la filière InP et de la filière GaN," thesis of doctorat, University of Lille 1, 1998.

[12] J. L. Thobel, "Simulation Monte Carlo du transport électronique et des phénomènes de diffusion dans les systèmes à base de semi-conducteurs III-V," University of Lille 1, 1980.

[13] S. Galden, "Etude du transistor bipolaire à double hétérojonction $\mathrm{Si} / \mathrm{SiGe} / \mathrm{Si}$ par la simulation Monte Carlo," University of Paris, 1992.

[14] O. Mouton, J. L. Thobel, and R. Fauquemberg, J. Appl. Phys., 1993, pp.10-74.

[15] A.F.M. Anwar, Senior Member, Shangli Wu, and Richard T, Webster, "Temperature dependent transport properties in $\mathrm{GaN}_{1} \mathrm{Al}_{\mathrm{x}} \mathrm{Ga}_{1-\mathrm{x}} \mathrm{N}$, and $\mathrm{In}_{\mathrm{x}} \mathrm{Ga}_{1-\mathrm{x}} \mathrm{N}$ semiconductors," IEEE Transactions on Electron Devices, vol. 48, No 3, March 2001, pp. 567-572.

[16] Maziar Farahmand et al., "Monte Carlo Simulation of Electron Transport in the III-Nitride Wurtzite Phase Materials System: Binaries and Ternaries," IEEE Transactions on Electron Devices, vol. 48, $\mathrm{N}^{\mathrm{O}} 3$, March 2001 pp. 535-542. 